\title{
Insulin-like growth factor (IGF)-I, IGF-binding protein (IGFBP)-1, and fibroblast growth factor (FGF) 21 serum levels in Chinese women with and without gestational diabetes
}

\author{
Donna Seto-Young ${ }^{1,2}$, Dimiter Avtanski ${ }^{1}$, Kim So-Young ${ }^{2}$, Vanessa $\mathrm{Sy}^{2}$, Emilia Liao ${ }^{1,2}$, George Liu ${ }^{2}$, Stephen Wan ${ }^{3}$, Martin Lesser ${ }^{4}$ and \\ Leonid Poretsky,2* \\ ${ }^{1}$ Division of Endocrinology and Friedman Diabetes Institute, Department of Medicine, Lenox Hill Hospital, Northwell Health, New York, USA \\ ${ }^{2}$ Division of Endocrinology, Department of Medicine, Mt. Sinai Beth Israel, New York, USA \\ ${ }^{3}$ Department of Obstetrics and Gynecology, Mt. Sinai Beth Israel, New York, USA \\ ${ }^{4}$ Biostatistics Unit, The Feinstein Institute for Medical Research, Northwell Health, Manhasset, USA
}

\begin{abstract}
Background: Although Asians are generally characterized by lower body mass index (BMI) compared to Caucasians, the prevalence of gestational diabetes mellitus (GDM) among Asian women is higher. Our previous studies found that, like the Caucasians, pregnant Chinese women show difference between GDM and nonGDM in the levels of total adiponectin. However, there is no difference in other inflammatory markers such as CRP, TNF $\alpha$, IL-6 or MCP-1. The aim of the present study was to assess the IGF-I, IGFBP-1, and FGF21 levels in Chinese-American women with and without GDM.

Methods: The study involved 230 consecutively recruited pregnant subjects (191 without and 39 with GDM), 18-40 years of age and 24-28 weeks of gestation.

Results: GDM group had significantly higher levels of $\mathrm{HbA}_{1}$, 3-hour oral glucose tolerance test (3h-OGTT) and fasting insulin and no different BMI values when compared to Chinese women without GDM. Unadjusted comparisons demonstrated that IGF-I and FGF21 levels were significantly higher, and those of IGFBP-1 significantly lower in the GDM group compared to the non-GDM group. Adjusted analyses for age, BMI, HbA, 1 -hour glucose challenge test (1H-GCT), and insulin levels, confirmed the higher IGF-I levels in Chinese women with GDM supporting previous studies in Caucasian women.
\end{abstract}

Conclusions: These results demonstrate that, similarly to Caucasians, IGF-I may play a role in the pathophysiology of GDM in Chinese women.

\section{Novelty statement}

- Chinese women with gestational diabetes mellitus (GDM) demonstrate higher IGF-I blood levels compared to those without GDM.

- IGF-I may play a role in the pathophysiology of GDM.

\section{Introduction}

Gestational diabetes mellitus (GDM) is defined as any degree of glucose intolerance with onset or first recognition during pregnancy [1]. The prevalence of GDM varies between $2 \%$ and $17 \%$ among the different ethnic groups [2], with 5.0-7.4\% prevalence among the Asian women [3] and 6.4\% prevalence among the US Chinese women [4].

Previous studies showed that the white adipose tissue cytokine, adiponectin, and in particular its high-molecular circulating form, has insulin-sensitizing actions and is negatively associated with type 2 diabetes mellitus (T2DM) and GDM [5-8]. Our previous study in pregnant Chinese-American women showed that total adiponectin levels, rather than the high-molecular weight adiponectin levels, most consistently correlate with the insulin sensitivity parameters [9]. Women without GDM who had failed a 1-hour 50 gram oral glucose challenge test ( $1 \mathrm{~h}-\mathrm{GCT} \geq 135 \mathrm{mg} / \mathrm{dL}$ ) with or without one abnormal glucose value during the 3-hour 100 gram glucose tolerance test (3h-OGTT), exhibited lower levels of total adiponectin. In addition, total adiponectin negatively correlated with insulin resistance markers (insulin, $1 \mathrm{~h}-\mathrm{GCT}, \mathrm{HbA}_{1 \mathrm{c}}$, and $\mathrm{BMI}$ ). In the current study, we analyzed the relationships between fibroblast growth factor (FGF)21, insulin-like growth factor-I (IGF-I), or insulin-like growth factor binding protein-1 (IGFBP-1) and markers of glucose tolerance (insulin, lh-GCT, $\mathrm{HbA}_{1 \mathrm{c}}$, BMI, and age) in Chinese-American pregnant women.

Insulin-like growth factor (IGF)-I, produced in the liver, acts as a primary mediator of the pituitary growth hormone $(\mathrm{GH})$. It mimics the actions of insulin including stimulation of glucose uptake and

Correspondence to: Leonid Poretsky, M.D, Division of Endocrinology and Metabolism, Department of Medicine, Lenox Hill Hospital, 110 East 59th Street, Suite 8B, Room 800, New York, NY 10022, Tel: 1-212-434-4662; Fax: 1-212-4344664; E-mail: lporetsky@northwell.edu

Key words: IGF-I, IGFBP-1, FGF21, GDM

Received: September 09, 2017; Accepted: September 28, 2017; Published: October 02,2017 
inhibition of gluconeogenesis. IGF-I function is modulated by IGFbinding proteins of which IGFBP-1 is under inhibitory control of both insulin and IGF-I $[10,11]$.

FGF21 is a protein that stimulates glucose uptake in adipocytes acting synergistically with insulin [12]. Studies have shown that treatment of diet-induced obese or leptin deficient (ob/ob) or leptin receptor deficient $(\mathrm{db} / \mathrm{db})$ obese mice obese mice with FGF21 or overexpression of FGF21 in transgenic mice resulted in reduced body weight and adiposity and improved insulin sensitivity [13-14]. Blood levels of FGF21 are elevated in T2DM patients [15,16], but the data for GDM patients are controversial, showing no different [12] or elevated [18] FGF21 blood levels. Indeed, recent studies demonstrated increased placental mRNA and protein FGF21 expression in GDM patients $[17,18]$, but no difference in FGF21 cord blood levels [18].

Although Asian women are generally characterized by lower obesity rate, the GDM prevalence among Asians is approximately twice as high as that in Caucasian women (6.4\% vs. 3.8\%) [4]. The aim of this study was to evaluate the roles of IGF-I, IGFBP-1, and FGF21 in the pathogenesis of GDM in pregnant Chinese women in an effort to assess whether these markers relate differently to GDM in Chinese compared to the literature on Caucasians. To our knowledge, there have been no studies examining the involvement of these factors in the GDM in Asian populations.

\section{Methods}

\section{Subjects}

The study was approved by Mt. Sinai Beth Israel Hospital's Institutional Review Board. Chinese-American subjects were recruited by Drs. Stephen Wan and Doris Tan from their practices. Consent forms translated into Chinese were given and the consent was obtained from all women involved in the study. Inclusion criteria were as follows: women of Chinese ethnicity, 18 to 40 years of age and 24-28 weeks of gestation. Exclusion criteria were as follows: diagnosis of hepatitis B or other infectious diseases (Herpes virus, Streptococcus $B$ carrier, Chlamydia, and Candida), thyroid dysfunction, thalassemia, and a history of miscarriages or infertility with use of in vitro fertilization (IVF).

Blood samples were obtained from subjects one hour after 50-gram oral glucose challenge test (1h-GCT). The serum samples were sent to Quest Diagnostics for glucose and $\mathrm{HbA}_{1 \mathrm{c}}$ analysis. Additional blood samples were collected at the same time, centrifuged at $2000 \mathrm{rpm}$ for 10 minutes to separate serum from the cells, and the sera were stored at $-80^{\circ} \mathrm{C}$ for further biochemical marker measurements.

\section{Identifying GDM}

A 2-step test was used to diagnose GDM. 50 g glucose was administered and the serum glucose level was measured one hour later. The serum glucose value of $135 \mathrm{mg} / \mathrm{dL}$ was used as a threshold for $1 \mathrm{~h}-$ GCT. If subjects failed the $1 \mathrm{~h}-\mathrm{GCT}$ ( $\geq 135 \mathrm{mg} / \mathrm{dL}$ ), they underwent a 100-gram 3-hour oral glucose tolerance test (3h-OGTT) with capillary blood glucose levels measured at $0,1,2$, and 3 hours. Glucose levels were measured by finger-stick HemoCue ${ }^{\circ} \mathrm{Hb} 201+$ System glucometer (HemoCue, Brea, CA) since many study subjects refused to have blood drawn four times because of cultural beliefs about phlebotomy during pregnancy. The diagnosis of GDM was based on two or more glucose values at or above the threshold values: 0 hour $(95 \mathrm{mg} / \mathrm{dl}), 1$ hour $(180$ $\mathrm{mg} / \mathrm{dl}), 2$ hours $(155 \mathrm{mg} / \mathrm{dl})$, and 3 hours $(140 \mathrm{mg} / \mathrm{dl}$ ).

\section{Enzyme-linked immunosorbent assay (ELISA)}

Serum concentrations of biochemical markers (FGF21, insulin, IGF-I, and IGFBP-1) were measured using ELISA kits (ALPCO, Salem,
$\mathrm{NH})$. The intra- and inter-assay coefficients of variability $(\mathrm{CV})$ of the ELISA kits were as follows: IGF-I (5.1-6.67\% and 2.3-6.8\%), IGFBP-1 (2.5\% and $4.9-7.4 \%$ ), insulin (5.1\% and 6.7\%), FGF21 (4-5\% and 3.5-10.2\%).

\section{Statistical analyses}

230 consecutive patients were recruited and divided into two groups: GDM (191 patients) and non-GDM (39 patients). Demographic and clinical variables were compared (age, BMI, HbA 1 , 3h-OGCT, and insulin) using the two-sample $t$-test. Both the $t$-test and standard multiple linear regression were used to compare the two groups on each of the three markers (IGF-I, IGFBP-1, and FGF-21). The multiple regression method was used to compare markers after adjusting for age, BMI, $\mathrm{HbA}_{1 \mathrm{c}}$, $\mathrm{h}$-GCT, and insulin. Variable selection was determined using backward elimination, with group forced into the model. Results were considered significant if $\mathrm{p}<0.05$.

\section{Results}

The subjects' demographic and other variables (age, $\mathrm{BMI}, \mathrm{HbA}_{1 \mathrm{c}}$ $3 \mathrm{~h}$-OGCT, and insulin) are shown in Table 1. The two-sample $t$-test analysis showed that the GDM group, as expected, had significantly higher mean age $(\mathrm{p}<0.0029), \mathrm{HbA}_{1 \mathrm{c}}(\mathrm{p}<0.0023)$, 1h-GCT $(\mathrm{p}<$ $0.0001)$ as well as insulin levels $(\mathrm{p}<0.0001)$. There were no statistically significant differences in BMI between the two subject groups (Table 1).

IGF-I, IGFBP-1, and FGF21 data are shown in Table 2. The unadjusted comparisons of these markers showed that the serum levels of IGF-I and FGF21 were significantly higher in the GDM group compared to non-GDM ( $\mathrm{p}<0.0002$ and $\mathrm{p}<0.0098$, respectively). Conversely, the levels of IGFBP-1 were significantly lower $(\mathrm{p}<0.0144)$ in the GDM group compared to the non-GDM group. After adjustment for age, BMI, $\mathrm{HbA}_{1 \mathrm{c}}, \mathrm{HGCT}$, and insulin levels, IGF-I level was still significantly higher $(\mathrm{p}<0.0332)$ in the GDM group, however the levels of FGF21 and IGFBP-1 were no longer significantly different between the two groups (Table 2).

\section{Discussion}

Previous epidemiological studies demonstrated that ethnic background is an important factor in the development of GDM [19]. Asian and Pacific Islander women have higher predisposition to GDM compared to all other ethnical groups [4]. Compared to Caucasian women, the prevalence of GDM among Chinese women is approximately twice as high [4]. It is known that increased body weight before and during pregnancy [20-21] as well as higher weight gain velocity during pregnancy [22] are predisposing risk factors for the development of GDM. Importantly, this fact is inconsistent with the lower obesity rate among the Chinese, although previous reports

Table 1. Comparison on demographic and clinical variables.

\begin{tabular}{|c|c|c|c|}
\hline Variable & $\begin{array}{c}\text { Non-GDM } \\
\text { (n) }\end{array}$ & $\begin{array}{c}\text { GDM } \\
\text { (n) }\end{array}$ & $\boldsymbol{p}$ value \\
\hline Age $[\mathrm{yrs}]$ & $30.27 \pm 4.66(191)$ & $32.77 \pm 5.09(39)$ & 0.0029 \\
BMI [kg/m²] & $24.08 \pm 2.84(190)$ & $24.95 \pm 3.64(39)$ & $\mathrm{NS}$ \\
HbA1C [\%] & $5.16 \pm 0.33(178)$ & $5.35 \pm 0.31(36)$ & 0.0023 \\
1h-GCT [mg/dl] & $113.70 \pm 22.75(191)$ & $161.05 \pm 18.32(37)$ & 0.0001 \\
Insulin [ng/ml & $55.32 \pm 44.48(191)$ & $114.32 \pm 92.88(39)$ & 0.0001 \\
\hline
\end{tabular}

Table 2. Mean levels of candidate markers.

\begin{tabular}{|c|c|c|c|}
\hline Variable & $\begin{array}{c}\text { Non-GDM } \\
\text { (n) }\end{array}$ & $\begin{array}{c}\text { GDM } \\
\text { (n) }\end{array}$ & p value \\
\hline IGF-I $[\mathrm{ng} / \mathrm{ml}]$ & $178.19 \pm 69.89(180)$ & $233.48 \pm 102.20(38)$ & 0.0332 \\
IGFBP-1 [ng/ml] & $162.36 \pm 105.82(183)$ & $141.23 \pm 114.48(38)$ & 0.8338 \\
FGF21 $[\mathrm{pg} / \mathrm{ml}]$ & $33.12 \pm 21.90(189)$ & $48.84 \pm 44.13(38)$ & 0.3475 \\
\hline
\end{tabular}


showed that Asian women can develop insulin resistance at lower body mass index (BMI) values [23]. Our study did not show any statistically significant difference between the BMI values of non-GDM and GDM Chinese women, indicating that BMI may not be an important predictor of GDM among Chinese women. This phenomenon may be due to the higher body fat percentage among the Asians compared to Caucasians or the differences in the spatial distribution of the white adipose tissue depots. In fact, Asian women have a greater central adiposity than Caucasians, which could partially explain the higher prevalence of insulin resistance and diabetes [24,25].

Our previous studies suggested that both total and high molecular weight adiponectin may be important contributors to GDM in Chinese-American women, but unlike the Caucasians, Chinese women displayed no significant correlations between markers of glucose tolerance and inflammation [9]. The goal of this study was to compare FGF21, IGF-I or IGFBP-1 and markers of glucose tolerance (insulin, 1h-OGTT, $\mathrm{HbA}_{1 \mathrm{c}}$, BMI or age) between pregnant Chinese-American women with or without GDM.

As expected, our data show that the GDM group had higher levels of $\mathrm{HbA}_{1 \mathrm{c}}$, 1h-OGTT glucose and insulin levels compared to non-GDM group. Additionally, IGF-I levels were also elevated in the GDM compared to the non-GDM subjects. It is known that IGF-I mimics insulin in stimulating glucose uptake as well as in inhibiting gluconeogenesis [11]. IGF-I also plays an important role during gestation in placental development and function [26]. Elevated levels of IGF-I have been associated with septal hypertrophic cardiomyopathy [27]. The results from this study confirmed previous observations in Caucasian women that IGF-I levels with or without adjustment for age and BMI are higher in GDM [28].

Our unadjusted results also indicate that the levels of IGFBP-1 may be lower in GDM, supporting previous observations in Caucasians [29]. Previous studies showed that serum IGFBP-1 correlates negatively with circulating insulin levels, and it was suggested that IGFBP-1 may be a marker for hyperinsulinemia in obese menopausal women [30]. Although the role of IGFBP-1 in the development of GDM is not clear, lower IGFBP-1 levels may result in higher circulating free IGF-I levels, contributing to fetal macrosomia [31]. However, this hypothesis is not conclusive since, after adjusting for age and BMI, we did not find a statistically significant difference in the levels of IGFBP-1 between the two groups.

In this study we were also interested in assessing the association of FGF21 with GDM, since FGF21 was previously found to significantly correlate with markers of insulin resistance and dyslipidemia [32] and to play a role in the pathogenesis of T2DM [33]. Our data indicated significantly higher unadjusted serum FGF21 levels in GDM women compared to the healthy pregnant controls. After adjusting for age and BMI, however, the difference was no longer significant, suggesting that FGF21 may not play a role in the development of GDM in Chinese.

Our study has a number of limitations. The subjects without GDM were significantly younger than those in the GDM group. It is well known that age plays a major role in the development of glucose intolerance [34]. We were also not able to obtain data on the pregestational BMIs of our subjects, since they presented to the clinic for the first time at 8-14 gestational week.

We measured glucose values during the 3h-OGTT by using $\mathrm{HemoCue}^{\oplus} \mathrm{Hb} 201+$ System glucometer because of cultural beliefs, as described above. HemoCue ${ }^{\oplus} \mathrm{Hb} 201+$ System glucometer demonstrates negative bias of $8 \%$ when compared to Vitros 5,1 FS analyzer (Ortho
Table 3. Differences between Chinese and Caucasian women with GDM. $\uparrow$ - increased in GDM; $\downarrow$ - decreased in GDM; $\leftrightarrow$ - no difference between GDM and non-GDM.

\begin{tabular}{|c|c|c|}
\hline Risk Factor / Marker & $\begin{array}{c}\text { Chinese } \\
\text { (our studies) }\end{array}$ & $\begin{array}{c}\text { Caucasians } \\
\text { (literature) }\end{array}$ \\
\hline Age & $\uparrow$ & $\uparrow$ \\
BMI & $\leftrightarrow$ & $\uparrow$ \\
Free Adiponectin & $\downarrow$ & $\downarrow$ \\
Total Adiponectin & $\downarrow$ & $\downarrow$ \\
Insulin & $\uparrow$ & $\uparrow$ \\
IGF-I & $\uparrow$ & $\uparrow$ \\
FGF21 & $\leftrightarrow$ & $\leftrightarrow$ \\
IGFBP-1 & $\leftrightarrow$ & $\leftrightarrow$ \\
\hline
\end{tabular}

Clinical Diagnostics, Neckargemund, Germany) with within-run imprecision of $2.5-5.8 \%$ and between-run imprecision of 3.1-5.1\%.

To our best knowledge this is the first study of the examined markers which involved pregnant Chinese women. That no Caucasian subjects were used as controls is another weakness of the study. Thus, the comparisons between the findings in Chinese and Caucasians were made based on the literature.

It is important to note that the findings from our study may not be representative of the general Chinese population in the United States or China, since we recruited the patients only from two obstetrics and gynecology clinics located in New York City's Chinatown area.

In summary, the results of our study demonstrate that, similarly to Caucasians, higher serum IGF-I levels are present in Chinese-American women with GDM compared to Chinese-American women without GDM (Table 3). Further studies are needed to better understand the role of IGF-I in the pathophysiology of GDM in both Asians and Caucasians.

\section{Acknowledgments}

Funding was provided by the Gerald J. and Dorothy R. Friedman New York Foundation for Medical Research, by Chinese-American Medical Society \& Chinese-American Independent Practice Association Research Fund, and by the Yen Family Foundation. We thank Dr. Doris Tan, MD for helping with various aspects in the study and Yael Hirth and Arthur Guffanti, PhD for reviewing the manuscript.

\section{Disclosure}

None of the authors have any financial conflict of interest in regard to the materials included in this manuscript.

\section{References}

1. American Diabetes Association (2004) Gestational diabetes mellitus. Diabetes Care 27: S88-90. [Crossref]

2. Hunt KJ, Schuller KL (2007) The increasing prevalence of diabetes in pregnancy. Obstet Gynecol Clin North Am 34: 173-199. [Crossref]

3. Ferrara A, Hedderson MM, Quesenberry CP, Selby JV (2002) Prevalence of gestational diabetes mellitus detected by the national diabetes data group or the carpenter and coustan plasma glucose thresholds. Diabetes Care 25: 1625-1630. [Crossref]

4. Chu SY, Abe K, Hall LR, Kim SY, Njoroge T, et al. (2009) Gestational diabetes mellitus: all Asians are not alike. Prev Med 49: 265-268. [Crossref]

5. Berg AH, Combs TP, Du X, Brownlee M, Scherer PE (2001) The adipocyte-secreted protein Acrp30 enhances hepatic insulin action. Nat Med 7: 947-953. [Crossref]

6. Maeda N, Shimomura I, Kishida K, Nishizawa H, Matsuda M, et al. (2002) Dietinduced insulin resistance in mice lacking adiponectin/ACRP30. Nat Med 8: 731-737. [Crossref]

7. Nawrocki AR, Rajala MW, Tomas E, Pajvani UB, Saha AK, et al. (2006) Mice lacking adiponectin show decreased hepatic insulin sensitivity and reduced responsiveness to peroxisome proliferator-activated receptor gamma agonists. J Biol Chem 281: 2654 2660. [Crossref] 
Seto-Young D (2017) Insulin-like growth factor (IGF)-I, IGF-binding protein (IGFBP)-1, and fibroblast growth factor (FGF) 21 serum levels in Chinese women with and without gestational diabetes

8. Mazaki-Tovi S, Romero R, Vaisbuch E, Erez O, Mittal P, et al. (2009) Maternal serum adiponectin multimers in gestational diabetes. J Perinat Med 37: 637-650. [Crossref]

9. Kim SY, Sy V, Araki T, Babushkin N, Huang D, et al. (2014) Total adiponectin, but not inflammatory markers $\mathrm{C}$-reactive protein, tumor necrosis factor-a, interluekin- 6 and monocyte chemoattractant protein-1, correlates with increasing glucose intolerance in pregnant Chinese-Americans. J Diabetes 6: 360-368. [Crossref]

10. Sala A, Capaldi S, Campagnoli M, Faggion B, Labò S, et al. (2005) Structure and properties of the C-terminal domain of insulin-like growth factor-binding protein-1 isolated from human amniotic fluid. J Biol Chem 280: 29812-29819. [Crossref]

11. Poretsky L, Cataldo NA, Rosenwaks Z, Giudice LC (1999) The insulin-related ovarian regulatory system in health and disease. Endocr Rev 20: 535-582. [Crossref]

12. Lee DV, Li D, Yan Q, Zhu Y, Goodwin B, et al. (2014) Fibroblast growth factor 21 improves insulin sensitivity and synergizes with insulin in human adipose stem cellderived (hASC) adipocytes. PLoS One 9: e111767. [Crossref]

13. Kharitonenkov A, Shiyanova TL, Koester A, Ford AM, Micanovic R, et al. (2005) FGF-21 as a novel metabolic regulator. J Clin Invest 115: 1627-1635. [Crossref]

14. Coskun T, Bina HA, Schneider MA, Dunbar JD, Hu CC, et al. (2008) Fibroblast growth factor 21 corrects obesity in mice. Endocrinology 149: 6018-6027. [Crossref]

15. Chavez AO, Molina-Carrion M, Abdul-Ghani MA, Folli F, Defronzo RA (2009) Circulating fibroblast growth factor- 21 is elevated in impaired glucose tolerance and type 2 diabetes and correlates with muscle and hepatic insulin resistance. Diabetes Care 32: 1542-1546. [Crossref]

16. Chen C, Cheung BM, Tso AW, Wang Y, Law LS, et al. (2011) High plasma level of fibroblast growth factor 21 is an Independent predictor of type 2 diabetes: a 5.4-year population-based prospective study in Chinese subjects. Diabetes Care 34: 2113-2115. [Crossref]

17. Dekker Nitert M, Barrett HL, Kubala MH, Scholz Romero K, Denny KJ, et al. (2014) Increased placental expression of fibroblast growth factor 21 in gestational diabetes mellitus. J Clin Endocrinol Metab 99: E591-8. [Crossref]

18. Megia A, Gil-Lluis P, Näf S, Ceperuelo-Mallafré V, Gonzalez-Clemente JM, et al. (2015) Cord blood FGF21 in gestational diabetes and its relationship with postnatal growth. Acta Diabetol 52: 693-700. [Crossref]

19. Dornhorst A, Paterson CM, Nicholls JS, Wadsworth J, Chiu DC, et al. (1992) High prevalence of gestational diabetes in women from ethnic minority groups. Diabet Med 9: 820-825. [Crossref]

20. E. Institute of Medicine (US) and National Research Council (US) Committee to Reexamine IOM Pregnancy Weight Guidelines; Rasmussen KM, Yaktine AL, Weight Gain During Pregnancy: Reexamining the Guidelines. 2009.
21. Leng J, Shao P, Zhang C, Tian H, Zhang F, et al. (2015) Prevalence of gestational diabetes mellitus and its risk factors in Chinese pregnant women: a prospective population-based study in Tianjin, China. PLoS One 10: e0121029, 2015. [Crossref]

22. Di Cianni G, Volpe L, Lencioni C, Miccoli R, Cuccuru I, et al. (2003) Prevalence and risk factors for gestational diabetes assessed by universal screening. Diabetes Res Clin Pract 62: 131-137. [Crossref]

23. Retnakaran R, Hanley AJ, Connelly PW, Sermer M, Zinman B (2006) Ethnicity modifies the effect of obesity on insulin resistance in pregnancy: a comparison of Asian, South Asian, and Caucasian women. J Clin Endocrinol Metab 91: 93-97. [Crossref]

24. Park YW, Allison DB, Heymsfield SB, Gallagher D (2001) Larger amounts of visceral adipose tissue in Asian Americans. Obes Res 9: 381-387. [Crossref]

25. Fujimoto WY, Bergstrom RW, Boyko EJ, Leonetti DL, Newell-Morris LL (1995) Susceptibility to development of central adiposity among populations. Obes Res 3: 179S-186S. [Crossref]

26. Randhawa RS (2008) The insulin-like growth factor system and fetal growth restrictionn. Pediatr Endocrinol Rev 6: 235-240. [Crossref]

27. Hayati AR, Cheah FC, Yong JF, Tan AE, Norizah WM (2004) The role of serum insulin-like growth factor I (IGF-I) in neonatal outcome. J Clin Pathol 57: 1299-1301. [Crossref]

28. Matuszek B, Lenart-Lipińska M, Burska A, Paszkowski T, Smoleń A (2011) Increased serum insulin-like growth factor-1 levels in women with gestational diabetes. Adv Med Sci 56: 200-206. [Crossref]

29. Lindsay RS, Westgate JA, Beattie J, Pattison NS, Gamble G, et al. (2007) Inverse changes in fetal insulin-like growth factor (IGF)-1 and IGF binding protein-1 in association with higher birth weight in maternal diabetes. Clin Endocrinol 66: 322328. [Crossref]

30. Mogul HR, Marshall M, Frey M, Burke HB, Wynn PS, et al. (1996) Insulin like growth factor-binding protein-1 as a marker for hyperinsulinemia in obese menopausal women. J Clin Endocrinol Metab 81: 4492-4495. [Crossref]

31. Seto-Young D, Zajac J, Liu HC, Rosenwaks Z, Poretsky L (2003) The role of mitogenactivated protein kinase in insulin and insulin-like growth factor I (IGF-I) signaling cascades for progesterone and IGF-binding protein-1 production in human granulosa cells. J Clin Endocrinol Metab 88: 3385-3391. [Crossref]

32. Stein S, Stepan H, Kratzsch J, Verlohren M, Verlohren HJ (2010) Serum fibroblas growth factor 21 levels in gestational diabetes mellitus in relation to insulin resistance and dyslipidemia. Metabolism 59: 33-37. [Crossref]

33. Cheng X, Zhu B, Jiang F, Fan H (2011) Serum FGF-21 levels in type 2 diabetic patients. Endocr Res 36: 142-148. [Crossref]

34. Reaven G (2003) Age and glucose intolerance: effect of fitness and fatness. Diabetes Care 26: 539-540. [Crossref]

Copyright: $@ 2017$ Seto-Young D. This is an open-access article distributed under the terms of the Creative Commons Attribution License, which permits unrestricted use, distribution, and reproduction in any medium, provided the original author and source are credited. 